\title{
PHYSICAL PROPERTIES AND IN SILICO TOXICITY OF SODIUM ALGINATE- SULFAMERAZINE BIOPOLYMERIC FILMS FOR FOOD APPLICATIONS
}

\section{BABU BHAGATH YERRAMATHI, MANJULA KOLA* \& BEULAH ANNEM MUNIRAJ}

Food Technology Division, Department of Home Science, College of Sciences, Sri Venkateswara University, Tirupati-, Andhra Pradesh, India

\section{ABSTRACT}

Sodium alginate (SA) films were fabricated with sulfamerazine which is a type of long-acting antimicrobial agent and also care was taken to choose film-forming compounds from natural and non-contradictory materials that are safe with food contact. Films were doped with an antimicrobial agent at different concentrations, design and development were chiefly focused on the food packaging and preservation. Physical and biological properties were studied to understand the core functional characteristics and capabilities of the films. Physical properties like thickness, moisture content, solid mass, opacity, and water solubility rate were assessed and potential changes have been noted in different experimental films. DPPH free radical scavenging activity was showed potential inhibition against free radicals with regarding the concentration of film solution, a significant difference was noted in various experimental films. Toxicology of the film-forming compounds was predicted through in silico method, the safety and risk factors associated with the film-forming compounds were explored accordingly. Doping of sulfamerazine into the SA polymer matrix showed a significant effect on physical and biological properties and the same was attained in detail in the discussion part of the study.

KEYWORDS: Biopolymers, Sodium Alginate, Sulfamerazine, Antioxidant Activity, In-Silico Toxicit

Received: Apr 05, 2021; Accepted: Apr 25, 2021; Published: May 08, 2021; PaperId.: IJASRJUN202118

\section{INTRODUCTION}

Biopolymeric films are packaging or enrobing materials made with naturally occurring biopolymers which are nontoxic to humans and the environment and also, they get easily degraded in the environment being suffered from severe pollutants from synthetic polymers (Bourtoom, 2008). Besides, consumer awareness and safety concerns towards processed food products led new approaches to develop eco-friendly and renewable edible films/coatings that is easily degradable within the soil. Several researchers are working on the development of functional food packaging materials from naturally occurring biopolymers which are extracted or separated from various natural sources (Falgueraet al., 2011). Plants are the major section occupied in the availability of polymeric compounds that have unique film-forming properties (Yadav et al., 2015). The beneficial characteristics like availability, biodegradability, compatibility, and non-toxicity of naturally occurred polymers have been attracted since the last few decades and synthetic polymer producers are pioneered in the research and development of the bioplastic sector (Aeschelmann and Carus, 2015). Due to the extended research opportunities, technology development and innovations, bio-based films are emerging as alternate packaging materials and also reached a notable identity in the food packaging and preservation sector (Weber et al., 2002). Various global societies and agencies working for food safety, public health, and pollution control also giving more priority for development. Several foods and pharma industrial peoples have successfully adopted these biopolymers and established industrial use in drug and food ingredient delivery. However, some are at their ground stage and research was remained at the laboratory 
level, their use as edible polymers is not fully defined yet (Khalil et al., 2017).

Biopolymers are complex units comprise of carbohydrates, proteins, lipids, and polycyclic hydrocarbons with polymerization capability that imparts a state of physical nature used to develop a film like structures (Van de Velde and Kiekens, 2002). The film-forming capability, unique physical, and biological properties are close to the synthetic polymers especially used in food packaging (Rhim, 2007). General applications of these bio-polymeric materials known to minimize the water transmission rate and gaseous exchange (transmission of $\mathrm{CO}_{2}, \mathrm{O}_{2}$, and other gases), physical barrier property, and carrier for various functional bodies to enhance the packaging functionalities to be considered as ideal characteristics for the food packaging (Raybaudi-Massiliaet al., 2008). These functional characteristics were conditioned and improved by treating with various active materials, either they support the overall structure or a single factor of the film. Film functionality depends on the various factors like composition, drying temperature, $\mathrm{pH}$, type of biopolymer, cross-linking degree, chemical reactivity in between the film compounds, quality, and nature of the plasticizer used (Collaet al., 2006). Understanding these characteristic properties was an important aspect of designing and development. Physical, biological, and toxicological properties are few important prime objectives to study the compatibility and versatility of a biopolymeric film. Several research findings were noted in the literature regarding different types of films with active functions like antioxidant, antimicrobial, fortified, and physical barrier nature that associated completely with naturally occurring polymers like starch, agar, casein, chitosan, protein isolates, wax, cellulose, gelatin, plant gums, and exudates etc., (Mellinaset al., 2016). However, their existence as complete food packaging material was chiefly dependent on the availability and cost of the raw material. Besides, the safety of food contact was remained in the preliminary stage and needs more research findings to raise biopolymeric films as a complete alternative for synthetic, petrochemical-based packaging materials that can be used along with the foods without any objections. Today, there are a lot of biodegradable films including nanomaterials were commercially producing and are using the packaging of many food products (Wróblewska-Krepsztulet al., 2018). But, their safety with food contact, migration, and accidental consumption along with foods was unknown being as biodegradable, because their manufacturing process was involved with the use of several additives to regulate and enhance the packaging performance of the particular biopolymeric material (composite).

So, the present research study was designed to develop biopolymeric antimicrobial films with naturally occurring, non-toxic materials for food packaging and also, their possible toxicity patterns were predicted. Sodium alginate (SA) was selected as a film-forming biopolymer along with glycerol, calcium ions (divalent $\mathrm{Ca}^{2+}$ ), sulfamerazine (SMR) as functional additives to improve the film's performance. The characteristic properties as well as safety measures of sodium alginate was well reported in the literature (Rinaudo, 2008;Lee and Mooney, 2012). Few research findings have been reported on divalent ion crosslinked alginates and their related biopolymeric films with characteristic functional properties. The First time, Rhimet al. (2003) and Rhim (2004) studied calcium ion mediated crosslinking of sodium alginate polymers. Later, da Silva et al. (2009) conducted a study on calcium ions cross-linked alginate and pectin films. Their findings revealed that sodium alginate polymers were well reacted with divalent cations. However, sulfamerazine an antimicrobial agent for biological functions within the sodium alginate polymer matrix was not reported to our best knowledge. Sulfamerazinemimic, the para-aminobenzoic acid (PABA) and able to bind the active site of enzyme dihydropteroate synthetase (DHPS) and eventually block the synthesis of tetrahydrofolate which is a co-factor for the synthesis of thymidine which is essential for the synthesis of bacterial DNA and RNA (Adayet al., 2006; Sköld and Swedberg, 2017). Hence, the authors were focused to develop $\mathrm{Ca}^{2+}$ ion cross-linked sodium alginate polymer matrix loaded with a naturistic antimicrobial agent (sulfamerazine) to improve the biological activity of the SA films. Various physical and biological 
techniques were performed to understand the film performance and results were discussed by correlating with the previous data available in this particular area of interest. At present, authors were chiefly focused on the development and characterization only, real-time food packaging applications could be evaluated in the later stage of the research work.

\section{MATERIALS AND EXPERIMENTAL METHODS}

\subsection{Materials}

Sodium alginate (algin) sulfamerazine were purchased from Sigma Aldrich, Mumbai, India. Other chemicals likeacetic acid glacial (100\%), calcium carbonate (extra pure), glycerol (purified) were purchased as the analytical grade from Merk specialties Pvt.Ltd., Mumbai, India.

\subsection{Preparation of the Film-Forming Solution}

A Film-forming solution was prepared according to the procedure followed by Benavides etal. (2012) with modifications. Various concentrations of SMR i.e., $0.6,1.2$, and $1.8 \mathrm{mg}$ (per $\mathrm{ml}$ of film-forming solution) was added to the solution containing $2 \% \mathrm{w} / \mathrm{v}$ of SA, aneat sodium alginate film was made without SMR for the comparison and labelled as standard, SMR60, SMR120, and SMR180. SMR solution was prepared by dissolving a $1 \mathrm{mg} / \mathrm{ml}$ ratio in absolute ethanol to get a completely solubilised mixture (Delgado and Martínez 2013). $2 \%$ of sodium alginate was exactly weighed and added to the distilled water taken in the round bottom flask, magnetically stirred at $70 \pm 2^{\circ} \mathrm{C}$ for an hour in rota-mantle. During the stirring process, glacial acetic acid was added to the solution to get a uniform homogenous mixture without lumps followed by calcium carbonate $(0.03 \mathrm{~g} / \mathrm{g}$ of SA) and glycerol $(1 \mathrm{ml} \mathrm{v} / \mathrm{v})$. A dissolved SMR solution was added to the film-forming solution $30 \mathrm{~min}$ before at the end of the reaction/process. The solution was again magnetic stirred for about 30 minutes at $65 \pm 2^{\circ} \mathrm{C}$ to allow evaporation of ethanoland the solution was filtered to obtain clear liquid without any lumps/sediments.

\subsection{Film Casting}

The solvent casting heat evaporation method was followed to develop the SA composite films, the process method was optimized according to the laboratory procedure followed by Han and Wang (2017) and the schematic representation was presented in Figure 1. The film-forming solution was poured into the $8 \times 1.7 \mathrm{~cm}$ glass Petri plates up to the mark previously quantified and measured up to $20 \mathrm{ml}$ per dish. Experimental films were dried in a vacuum oven at $52 \pm 2^{\circ} \mathrm{C}$ for about 48 hours. After complete drying, films were peeled off from the Petriplates and conditioned in a desiccators for further characterization. 


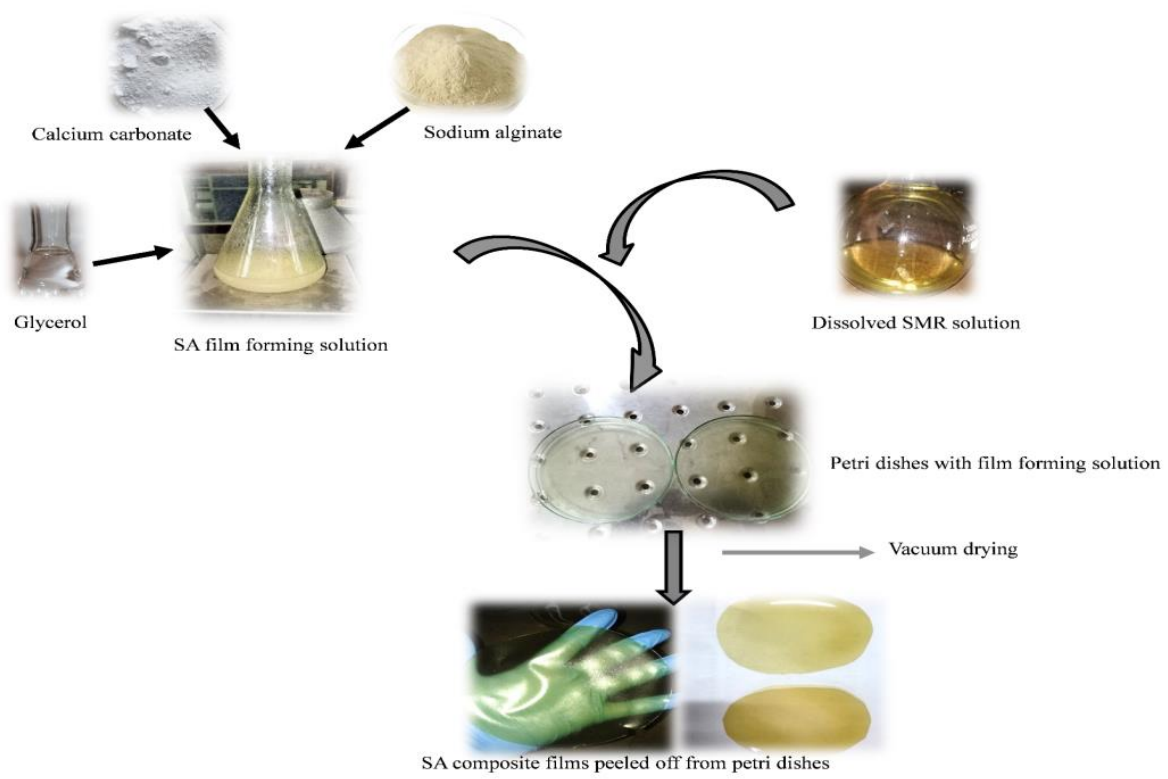

Figure 1: The Schematic Presentation of Processing and Casting of SA Composite Biopolymeric Films Loaded with SMR at Different concentrations.

\subsection{Thickness}

Films were measured with the micrometer (Insize 0-25mm digital outside micrometer 3109 series, accuracy $\pm 0.003 \mathrm{~mm}$, resolution $0.001 \mathrm{~mm}-0.00005$, INSIZE CO.,LTD). Before measuring, the micrometer was standardized with the standard piece and ensures the zero-measure range. Dry films were measured randomly in multiple points and the average was taken as the final thickness of the films (Rezvanianet al., 2016).

\subsection{Moisture Content and Solid Mass}

Moisture content in SA composite films was estimated according to the procedure followed by Mostafa vietal. (2016) with proper modifications. Films were exactly measured and cut into $3 \mathrm{~cm} \times 2 \mathrm{~cm}(\mathrm{~L} \times \mathrm{W})$ to maintain the uniform size of the samples. The initial weight (Iw) of the film placed in the silica crucible was measured, then after films were exposed to the $120^{\circ} \mathrm{C}$ in a muffle furnace (INDFURR Model-India) for $12 \mathrm{~h}$, cooled down for overnight, and final weight (Fw) was taken. The reduction in mass of the films was calculated using the below formula, the same was considered final moisture content and final weight (Fw) of the sample (solid mass).

$$
\begin{aligned}
& \text { Moisture content }(\%)=\frac{\mathrm{Iw}-\mathrm{Fw}}{\mathrm{Sw}} \times 100 \\
& \text { Total solid } \operatorname{mass}(\%)=\frac{\mathrm{Fw}-\mathrm{Mc}}{\mathrm{Sw}} \times 100
\end{aligned}
$$

Where, Iw= Initial weight of the dry film, $\mathrm{Fw}=$ final weight of the dry film, $\mathrm{Sw}=$ Weight of the sample taken for the experiment.

\subsection{Opacity/Light Barrier Properties}

The opacity of the experimental films was evaluated according to the procedure followed by the Soazoetal. (2015) with few modifications. The transmittance of the SA biopolymeric films contained different concentrations of SMR that were analyzedin triplicates with the absorbance and transmittance obtained from the UV-V is-spectrophotometer (GENESYS 
10S UV-VIS Spectrophotometer, Thermo Scientific, Japan). Films were cut and placed in the cuvettes and transmittance was recorded at $600 \mathrm{~nm}$. The scanning process was repeated trice for every film. Based on the transmittance of the light, the opacity of the samples was calculated with the below-mentioned formula.

$$
\text { Opacity }=100-X
$$

Where $100=$ Standard transmittance at $600 \mathrm{~nm}$ and $X=$ film transmittance read at $600 \mathrm{~nm}$.

\subsection{Water Solubility Rate}

The water solubility of SA composite films was estimated according to the method followed by Roger etal. (2006) with modification. Films were evaluated in triplicates as the percentile value of dry film dissolved in distilled water upon $24 \mathrm{~h}$ contact with water. The film pieces measured $1 \times 1 \mathrm{~cm}$ was made and treated with distilled water. The initial dry weight was recorded and the same films were immersed in $50 \mathrm{ml}$ of distilled water with periodic stirring for $24 \mathrm{~h}$ at room temperature (Appox. $28 \pm 2^{\circ} \mathrm{C}$ ). Films were taken out and dried in a hot air oven at $60 \pm 2^{\circ} \mathrm{C}$ for $48 \mathrm{~h}$ (the temperature and time used for the casting of experimental films) to record the final dry weight. Difference between the initial and final dry weight concerning the initial dry weight, the percentile value of solubility was reported.

$$
\text { Water solubility }(\%)=\frac{\mathrm{Wi}-\mathrm{Wf}}{\mathrm{Wi}} \times 100
$$

Where, $\mathrm{Wi}=$ Initial weight of the dry film, $\mathrm{Wf}=$ final weight of the dry film treated with water, $\mathrm{Mf}=$ final weight of the wet film.

\subsection{DPPH Free Radical Scavenging Activity}

DPPH free radical scavenging activity of the films was performed according to the method followed by Ravi etal. (2017) with modifications. Radical scavenging activity was measured based on the inhibition of DPPH (1,1- diphenyl-2-picrylhydrazil) as standard free radical. $0.6 \mathrm{mM}$ DPPH was dissolved in ethanol and $0.5 \mathrm{~mL}$ of this solution was taken, mixed with $0.5 \mathrm{mg}$ of different composition of films. The volume of this reaction mixture was taken upto $5 \mathrm{~mL}$ with ethanol and made completely dissolved. The reaction mixture was incubated for 30 minutes in dark conditions. An incubated reaction mixture was read at $517 \mathrm{~nm}$ using UV-Vis spectrophotometer against ethanol as blank, ascorbic acid was used as a standard to compare the experimental results. The percentage of DPPH free radical inhibition was calculated by followed equation.

$$
\text { DPPH radical scavenging activity }(\%)=\frac{\mathrm{Ac}-\mathrm{As}}{\mathrm{Ac}} \times 100
$$

Were, Ac-control reading, As-sample reading.

\subsection{In Silico Toxicity of Film-Forming Compounds}

In silico methods include Lipinski's rule of five has been potential for the screening of drug-like compounds to prevent wasting time on toxicity and safety assessments. Consequently, the selected bio-film making compounds contain physicochemical properties, pharmacokinetics absorption, distribution, metabolism, and excretion-toxicity (ADMET)), lipophilicity, water-solubility, drug-likeness, and synthetic accessibility properties were analyzed using robust Swiss ADME tool (Dainaet al., 2017). The data from the in silico analysis provides information about the safety and risk rages of target compounds, which potentiated them as good bio-film makers and also provide understandable pinpoints to make a decision regarding that particular film-forming compounds. 


\subsection{Statistical Analysis}

Data output obtained through various experiments was analyzed with Excel software (Ms office 2014, Microsoft Inc.). ANOVA (Analysis of variance) single factor was used to distinguish the significant difference between experimental films at $\mathrm{p}<0.05$ and appropriate plots were drawn with Origin data analysis and graphing software (Version 8), Origin Lab Corporation, USA.

\section{RESULTS AND DISCUSSION}

\subsection{FilmThickness}

The thickness of the experimental films were shown in Figure 2. Results clearly show that there was no significant difference $(p<0.05)$ between the individual films loaded with different concentrations of SMR. Because, the composition of blend solution distributed with equal quantity and the constant ratio of film-forming compounds in all experimental films, only differ in SMR concentration. Uniformly measured, a constant volume of blend solution was maintained during the film casting. However, there was a little difference was observed in thickness, but its impact on physical and mechanical properties was negligible. Thickness similarity for all biopolymeric films was an essential factor, because it shows an impact on physical, mechanical, and biological properties referred to as the study of the behavior of the films. In the present study, the impact of thickness on film properties was minimized as no significant difference in thickness between the experimental films.

\subsection{Moisture Content and Solid Mass}

Moisture content (MC) and total solid mass (TSM) of the experimental films were presented in Figure 2. MC of 'standard, SMR60, SMR120, and SMR180' SA composite films were ' $68.96 \%, 65 \%, 64.14 \%, 63.63 \%$ whereas TSM was 31.03\%, $35 \%$, 35.86, 36.36' respectively. According to the data, little reduction in MC was observed in order 'standard $>$ SMR60 $>$ SMR120 $>$ SMR180' due to the increased solid mass in contrast with the sulfamerazine (SMR). Because all four experimental films shared equal proportions of film-forming compounds but differ in SMR concentration only. Experimental films were significantly $(\mathrm{p}<0.05)$ different and gradual reduction in the MC and increase in TSM was observed as consequences of the crystal polymorph structure of SMR that affect the solid mass of sodium alginate films along with glycerol concentration, it increases the moisture content because of its water holding capacity (Aitipamulaet al., 2012). So, the concentration of SMR was indirectly proportional to the MC vice versa directly proportional to the TSM and it might be the key factor that affects the moisture and solidity of the experimental films. The tensile strength of the films was also a witness for the above changes because the data from the figure shows a gradual increase for TS in ascending order with the increased SMR concentration and consequently decreased moisture level. The similar findings were reported by Rangel-Marrón et al. (2013) who investigated the effect of sodium alginate and glycerol concentration on moisture content of the edible films. They explored that the concentration of film compounds was indirectly proportional to the moisture content due to low concentrations of polysaccharides allow greater availability of free water. Overall, the study describes the counter effect between available solidity and moisture content of the experimental films. Alboofetileh et al. (2013) investigated and explored the effect of montmorillonite on alginate film properties and similar findings to the present study were noted regarding the counter effect between solidity and moisture content. In their study, they observed that the moisture content was gradually decreased with the increase of solid mass in the form of montmorillonite and polymer concentration. Finally, our study concluded that the decline of MC was accelerated through increased SMR concentration in SMR180 film which contains the highest percent of solid mass (36.37) among the experimental films. 


\subsection{Water Solubility Rate}

Figure 2 shows the water solubility rate (WSR) of SA composite films loaded with SMR at different concentrations. In this study, calcium ions and glycerol were thought to be the key factors that affect the WSR of SA films, because these compounds have participated in the cross-linking and plasticizing process of the film-forming biopolymers thereby it resists the water solubility. Cross-linking and plasticizing patterns increase film stability with water and made them more resistant to the hydration. WSR of standard, SMR60, SMR120, and SMR180 films were 90.79\%, 49.12\%, 41.16\%, and $36.35 \%$ respectively which are statistically more significant at $p<0.05$. According to the data presented in Figure 2, standard films made without a cross-linking agent and SMR dissolved rapidly than other experimental films. The reason might be the hydrophilic nature of the plasticizer used in the films, poor polymer network being contained hygroscopic film-forming compounds without cross-linking, and absence of water-insoluble (Very low solubility rate) SMR in standard films made itself more soluble. Cross-linked and SMR loaded film samples showed a low solubility rate than standard films. Moreover, a gradual decrease was observed with the addition of SMR. Low WSR was noted in SMR180 films containing a high concentration of SMR which is relatively insoluble in water $(202 \mathrm{mg} / \mathrm{L})$ with sufficient $\mathrm{Ca}^{2+}$ ions for cross-linking (Delgado and Martínez, 2013). The addition of poor water-soluble SMR and enough ionic cross-linking made the films more water-resistant than standard film, because carboxylic groups and hydroxyl groups present in the alginate polymers was cross-linked each other by calcium ions and formed a water-resistant complex polymer network (Rhim, 2004).

\subsection{Opacity/Transparency}

Opacity and transparency are the two important optical characteristics used to study the degree of light absorbance and transmittance through the film that resembles its optical integrity and nature of the composition. Controlling light transmission was an essential property for the films used in the coating or packing of certain food products because foods that are exposed to the light undergoes several biochemical reactions inside the food and triggered the unfavorable changes in nutritional quality. So, films with high opaqueness are considered for packing or enrobing most of the food products (Bekbölet, 1990). However, besides the light barrier property, clearness of the packaging material is an essential thing to state the quality and purity of the packaging films and also to give visual clearness to the consumers to identify the quality of food products present inside the package. Light absorbance (Abs) and transmittance (T) values at $600 \mathrm{~nm}$ were used to calculate the opaqueness of the films to study typical response towards the light. Figure 2 show the opacity values for the SA films which were statistically significant atp $<0.05$. Light transmittance was decreased to the addition of SMR i.e., standard $>$ SMR60 $>$ SMR120 $>$ SMR180 which was effected on opacity in order 'SMR180 $>$ SMR120 $>$ SMR60 $>$ Standard because light transmittance was indirectly proportional to the opacity and also these factors were inversely correlated to each other. Hence, the low (3.03\%) and high (37.06\%) opaqueness was noted in 'standard' and 'SMR180' films contained lower and higher TSM accordingly based on SMR concentration. The data shows that the light absorption rate gradually went up with the increased TSM within the films due to the light-matter interactions. Light absorption was intensified with the increased solid matter present in the films and it was also evident that substances with more solid matter absorb more light than lite mattered ones (Britnellet al., 2013). Therefore, according to the experimental results, it is evident that films with low TSM resulted in low opacity than films with high TSM because the solid mass of the films depended on the concentration factor of SMR may be the reason behind the film TSM and thickness which are directly proportional to the film opacity. 


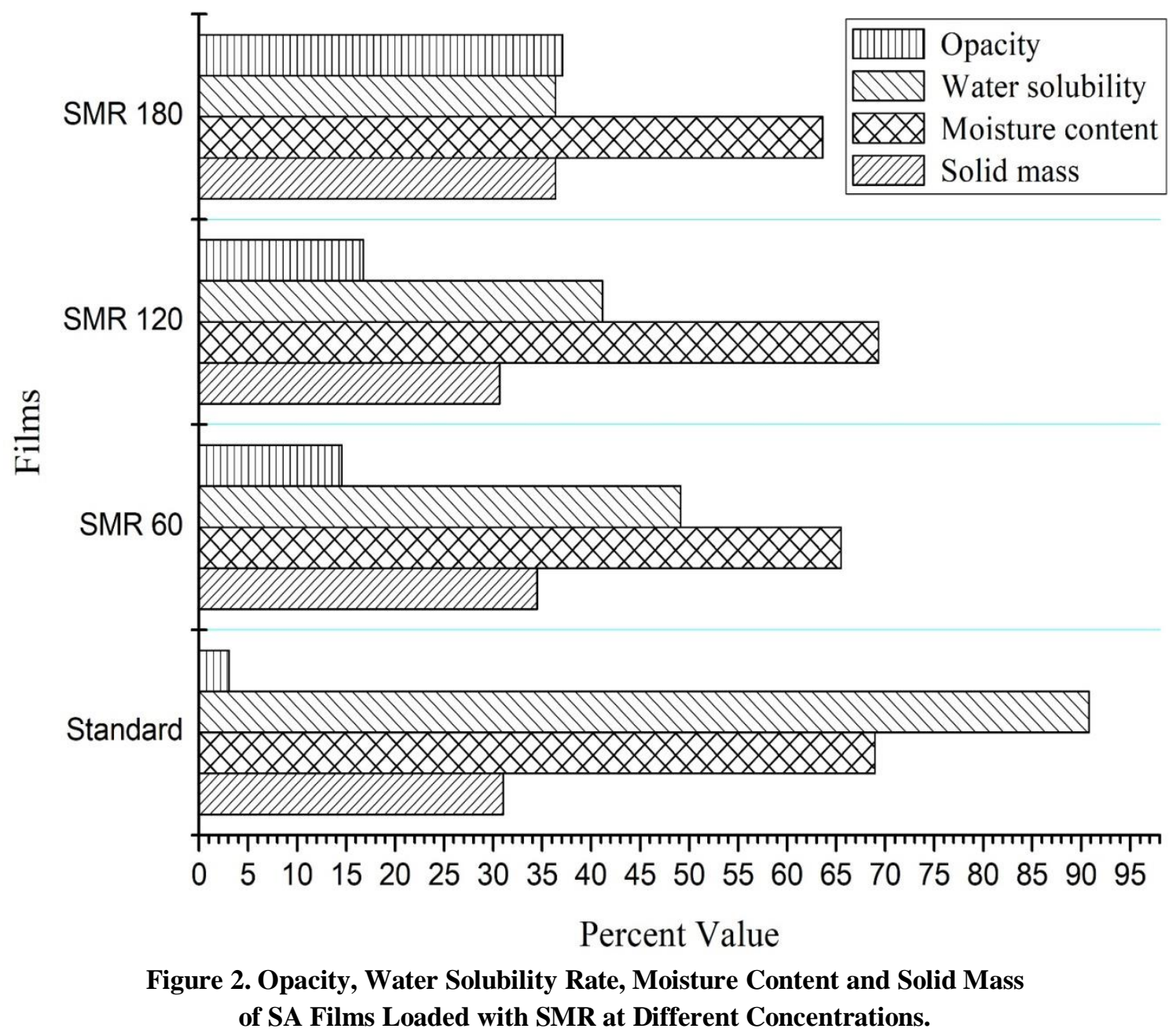

\subsection{AntioxidantActivity}

DPPH (2,2-diphenyl-1-picrylhydrazyl) free radical scavenging activity was one of the prominent methods used to understand the antioxidant activity of natural compounds. The reducing capacity of the materials was measured with the scavenging of DPPH free radicals. DPPH in deep purple colour is a commercial-free radical used to react with the electrondonating compounds. The reaction was terminated by neutralizing the free radicals and this phenomenon should be observed as a colour reduction from deep purple to pale yellow/colourless. Changes in colour intensity was a key factor which measured at $517 \mathrm{~nm}$ as absorbance of light in a spectrophotometer. The reduction rate in colour intensity was calculated and expressed as free radical scavenging activity of that particular compound.

SA itself was a good antioxidant agent containing enough hydrogen bond donors with an electrostatic attraction towards molecules with lone pair of electrons (Sellimiet al., 2015). The antioxidant activity of the SA composite films was evaluated based on the concentration depended on mode and the data was presented in Figure 3. All experimental films containing 2\% SA exhibited near similar range in DPPH radical scavenging activity even though loaded with SMR. However, a significant difference $(\mathrm{p}<0.05)$ in free radical scavenging activity was observed in between the experimental films. The results were following the Kok and Wong (2018) who reported free radical inhibition range of sodium alginate in between $62 \%$ to $75 \%$. The inhibition range was near stable in all the films within the same concentration range indicated the relativity of radical scavenging capacity between the various films. The percent of inhibition was slightly increased 
with the concentration of film solution i.e., 100, 200, 300, 400, and $800 \mu$ l, this increment was little deviated among the standard, SMR60, SMR120, and SMR180 biopolymeric films. According to the Figure 3, differently concentrated films and their DPPH radical inhibition percentile values of standard-400 $\mu \mathrm{l}$ (63.53\%), SMR60-200 $\mu \mathrm{l}$ (63.67\%), and SMR120$100 \mu \mathrm{l}$ (63.84\%); standard-200 $\mu \mathrm{l}$ (62.55\%), and SMR60-100 $\mu \mathrm{l}$ (62.34); SMR60-400 $\mu \mathrm{l}$ (66.21\%), and SMR120-400 $\mu \mathrm{l}$ (66.11\%); SMR120-200 $\mu \mathrm{l}$ (64.57\%), and SMR180-100 $\mu \mathrm{l}$ (65.18\%) shows no significance in radical scavenging activity. However, the highest $(74.01 \%)$ and lowest $(33.18 \%)$ percent of inhibition was noted in SMR180 at the concentration of $800 \mu \mathrm{l}$ and standard at the concentration of $100 \mu \mathrm{l}$. This outstretched range of radical inhibition was may be due to the variations in film thickness and concentration range of SA in the solution. According to Figure 2, differentiation in the thickness of the standard $(243.5 \mu \mathrm{m})$ and SMR180 $(259.8 \mu \mathrm{m})$ films which gained the radical inhibition percentage as minimum and maximum. Radical inhibition capability of the individual films was directly proportional to the thickness because of the increased mass of SA in more thickened films. All experimental films have near similar radical inhibition range indicated that the dependency of DPPH radical scavenging activity on sodium alginate concentration. The reference value for the DPPH free radical inhibition of sodium alginate was 74-75\% (Approx.), which strongly supported the above statements and also indicated the limited role of SMR for the antioxidant activity of SA composite films.

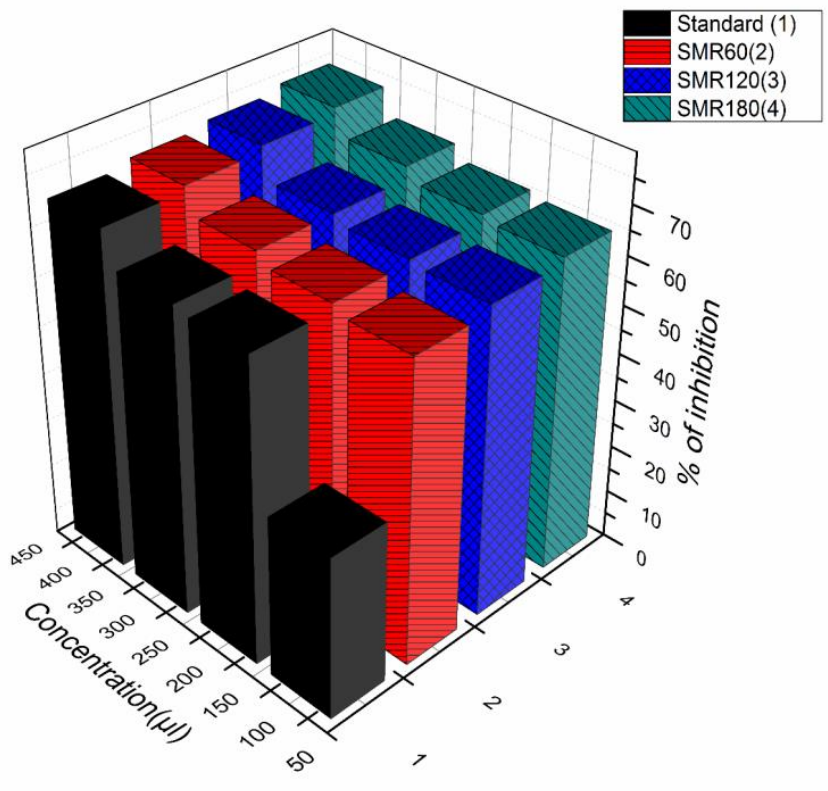

Figure 3: DPPH Free Radical Scavenging Activity of SA Biopolymeric Films Loaded with SMR at Different Concentrations.

\subsection{Toxicity and Safety of the Film-Forming Compounds}

The safety assessment of the compound is an essential parameter for a probable biologically active molecule recognition. Therefore, the specified bio-film-making compounds consist of pharmacokinetics properties were analysed using in silico methods through a robust Swiss ADME program. The predicted statistics for a set of six compounds are shown in Table 1. As shown in the table, the selected molecules indicated that good physicochemical properties such as molecular weight, $\mathrm{H}$ bond acceptors, H-bond donors, molar refractivity, and topological polar surface area (TPSA) values. According to the predicted n-octanol/water partition coefficient $(\log$ Po/w) values, one can observe that all the compounds show good 
lipophilicity values and indicated a strong agreement with the water solubility parameter. Consequently, the estimated solubility of compounds was provided as highly (2) and very soluble (4) classes. As per the predicted pharmacokinetic properties, one can observe that the compounds consist of high GI absorption (3), BBB permeant (0), Pgp substrate (2), CYP450 inhibitor activity (0), and reliable $\log \mathrm{Kp}(\mathrm{cm} / \mathrm{s})$ skin permeability scores. Moreover, they were provided with good bioavailability and synthetic accessibility (SA) scores. The structural alert fragments of compounds were predicted using pan assay interference compounds (PAINS), which indicate compounds don't have SAs, so they are characterized as non-toxic. Altogether, one can conclude that the selected film making compounds consists of good and reliable ADME assets, adaptable range scores, and non-toxic effects. Accordingly, regard compounds have been more potential for making food packing and coating formulations. Although, these sorts of studies are more probable for future food safety assessments and preparation of biopolymeric films.

Table 1: Admet Distribution and Toxicological Evaluation of Various Compounds used in the preparation of Experimental Biopolymeric Films

\begin{tabular}{|c|c|c|c|c|c|c|c|c|c|c|c|c|}
\hline \multirow[b]{2}{*}{ Compound } & \multirow[b]{2}{*}{ MW } & \multicolumn{8}{|c|}{ Physicochemical properties (RO5 Values) } & \multicolumn{2}{|c|}{ Lipophilicity } & \multirow{2}{*}{$\begin{array}{l}\text { Water solubility } \\
\text { Class }\end{array}$} \\
\hline & & H.A & A.HA & $\begin{array}{l}\text { Fraction } \\
\text { Csp3 }\end{array}$ & N.RB & H-BA & H-BD & MR & TPSA & $\begin{array}{l}\text { Consensus } \\
\text { Log P }\end{array}$ & $\begin{array}{l}\text { ESOL Log } \\
\mathrm{S}\end{array}$ & \\
\hline Sodrum Alginate & 216.12 & 14 & 0 & 0.83 & 1 & 7 & 4 & 34.4 & 130.28 & -5.38 & 0.36 & Highly soluble \\
\hline Sulfamerazine & 264.3 & 18 & 12 & 0.09 & 3 & 4 & 2 & 68.52 & 106.35 & 0.74 & -1.86 & Very soluble \\
\hline Calcium Carbonate & 100.09 & 5 & 0 & 0 & 0 & 3 & 0 & 6.77 & 63.19 & -0.92 & -0.38 & Very soluble \\
\hline Glycerin & 92.09 & 6 & 0 & 1 & 2 & 3 & 3 & 20.02 & 60.69 & -1.09 & 0.83 & Highly soluble \\
\hline
\end{tabular}

Table 1. (Cont.)

\begin{tabular}{|c|c|c|c|c|c|c|c|c|c|c|c|}
\hline \multicolumn{4}{|c|}{ Pharmacokinetics } & \multirow[b]{2}{*}{$\begin{array}{l}\text { CYP2C19 } \\
\text { inhibitor }\end{array}$} & \multirow[b]{2}{*}{$\begin{array}{l}\text { CYP2C9 } \\
\text { inhibitor }\end{array}$} & \multirow[b]{2}{*}{$\begin{array}{l}\text { CYP2D6 } \\
\text { inhibitor }\end{array}$} & \multirow[b]{2}{*}{$\begin{array}{l}\text { CYP3A4 } \\
\text { inhibitor }\end{array}$} & \multirow[b]{2}{*}{$\begin{array}{l}\log K p \\
(\mathrm{~cm} / \mathrm{s})\end{array}$} & \multicolumn{2}{|c|}{ Drug likeness } & \multirow{2}{*}{$\begin{array}{l}\text { Medicinal } \\
\text { chemistry }\end{array}$} \\
\hline $\begin{array}{l}\text { GI } \\
\text { absorption }\end{array}$ & $\begin{array}{l}\mathrm{BBB} \\
\text { permeant }\end{array}$ & $\begin{array}{l}\text { Pgp } \\
\text { substrate }\end{array}$ & $\begin{array}{l}\text { CYP1A2 } \\
\text { inhibitor }\end{array}$ & & & & & & $\begin{array}{l}\text { Lipinski } \\
\text { violations }\end{array}$ & $\begin{array}{l}\text { Bioavail } \\
\text { ability } \\
\text { Score }\end{array}$ & \\
\hline Low & No & Yes & No & No & No & No & No & -9.28 & 0 & 0.55 & 3.96 \\
\hline High & No & No & No & No & No & No & No & -7.81 & 0 & 0.55 & 2.37 \\
\hline High & Yes & No & No & Yes & Yes & No & No & -5.12 & 0 & 0.55 & 4.35 \\
\hline High & No & No & No & No & No & No & No & -8.11 & 0 & 0.55 & 1.31 \\
\hline High & No & No & No & No & No & No & No & -6.82 & 0 & 0.56 & 1 \\
\hline
\end{tabular}

\section{CONCLUSIONS}

Sodium alginate films were developed with SMR, glycerol, and $\mathrm{Ca}^{++}$ions as functional and cross-linking agents to impart and strengthen the physical, mechanical and biological responses towards the food packaging. Here, SMR was selected as a potential antimicrobial agent and glycerol as a plasticizing compound in contrast with SA as a source of natural polymers. Plasticized and cross-linked SA films with various concentrations of SMR was developed and tested against various characteristics optimized for potential packaging material. Total solid mass and moisture content were related to the solidity of the films and water solubility rate was chiefly dependent on the crosslinking degree along with the solidness. Mechanical properties were improved with the SMR concentration following the cross-linking degree achieved by calcium ions. Antioxidant activity was little influenced while antibacterial activity was directly proportional to the SMR 
concentration within the films. Accordingly, conflicts related to the safety of the film-forming compounds were assessed and predicted through the Swiss ADME tool. It results in overall good and reliable ADME assets as no toxic to make biopolymeric films for food packaging. In the present study, the authors have undertaken an account of physical, biological characterization and safety of films as their potentiality towards food packaging, its convenience and real-time compatibility for food packaging would be assessed yet.

\section{ACKNOWLEDGMENT}

The first author [Student ID: F1-17.1/2016-17/RGNF-2015-17-SC-AND-18494/(SAIII/Website)] is thankful to the University Grants Commission (UGC), New Delhi, India for providing research fellowship to carry out research work. The authors are also grateful to the 'Central Institute of Plastic Engineering and Technology (CIPET)', Vijayawada, India for their technical support.

\section{REFERENCES}

1. Aday, B., Sola, P., Çolak, F., \& Kaya, M. (2016). Synthesis of novel sulfonamideanalogs containing sulfamerazine/sulfaguanidine and their biological activities. Journal of enzyme inhibition and medicinal chemistry, 31(6), $1005-1010$.

2. Aeschelmann, F., \&Carus, M. (2015). Biobased building blocks and polymers in the world: capacities, production, and applications-status quo and trends towards 2020. Industrial Biotechnology, 11(3), 154-159.

3. Aitipamula, S., Chow, P. S., \& Tan, R. B. (2012). The solvates of sulfamerazine: structural, thermochemical, and desolvation studies. CrystEngComm, 14(2), 691-699.

4. Aitipamula, S., Chow, P. S., \& Tan, R. B. (2012). The solvates of sulfamerazine: structural, thermochemical, and desolvation studies. CrystEngComm, 14(2), 691-699.

5. Bekbölet, M. (1990). Light effects on food. Journal of Food Protection, 53(5), 430-440.

6. Benavides, S., Villalobos-Carvajal, R., \& Reyes, J. E. (2012). Physical, mechanical and antibacterial properties of alginate film: Effect of the crosslinking degree and oregano essential oil concentration. Journal of food engineering, 110(2), 232-239.

7. Bootman, M., \& Yamamoto, R. (1998). U.S. Patent No. 5,833,665. Washington, DC: U.S. Patent and Trademark Office.

8. Bourtoom, T. (2008). Edible films and coatings: characteristics and properties. International food research journal, 15(3), 237-248.

9. Britnell, L., Ribeiro, R. M., Eckmann, A., Jalil, R., Belle, B. D., Mishchenko, A., .. \&Novoselov, K. S. (2013). Strong lightmatter interactions in heterostructures of atomically thin films. Science, 340(6138), 1311-1314.

10. Colla, E., do Amaral Sobral, P. J., \&Menegalli, F. C. (2006). Amaranthus cruentus flour edible films: influence of stearic acid addition, plasticizer concentration, and emulsion stirring speed on water vapor permeability and mechanical properties. Journal of agricultural and Food Chemistry, 54(18), 6645-6653.

11. da Silva, M. A., Bierhalz, A. C. K., \&Kieckbusch, T. G. (2009). Alginate and pectin composite films crosslinked with Ca2+ ions: Effect of the plasticizer concentration. Carbohydrate polymers, 77(4), 736-742.

12. Daina, A., Michielin, O., \&Zoete, V. (2017). SwissADME: a free web tool to evaluate pharmacokinetics, drug-likeness and medicinal chemistry friendliness of small molecules. Scientific reports, 7(1), 1-13.

13. Delgado, D. R., \& Martínez, F. (2013). Solubility and solution thermodynamics of sulfamerazine and sulfamethazine in some ethanol+ water mixtures. Fluid Phase Equilibria, 360, 88-96. 
14. Dragostin, O. M., Samal, S. K., Dash, M., Lupascu, F., Pânzariu, A., Tuchilus, C., ... \&Profire, L. (2016). New antimicrobial chitosan derivatives for wound dressing applications. Carbohydrate polymers, 141, 28-40.

15. Falguera, V., Quintero, J. P., Jiménez, A., Muñoz, J. A., \&Ibarz, A. (2011). Edible films and coatings: Structures, active functions and trends in their use. Trends in Food Science \& Technology, 22(6), 292-303.

16. Han, Y., \& Wang, L. (2017). Sodium alginate/carboxymethyl cellulose films containing pyrogallic acid: Physical and antibacterial properties. Journal of the Science of Food and Agriculture, 97(4), 1295-1301.

17. Han, Y., Yu, M., \& Wang, L. (2018). Physical and antimicrobial properties of sodium alginate/carboxymethyl cellulose films incorporated with cinnamon essential oil. Food Packaging and Shelf Life, 15, 35-42.

18. Kaya, M., Demir, E., \&Bekci, H. (2013). Synthesis, characterization and antimicrobial activity of novel xanthene sulfonamide and carboxamide derivatives. Journal of enzyme inhibition and medicinal chemistry, 28(5), 885-893.

19. Khalil, H. A., Saurabh, C. K., Tye, Y. Y., Lai, T. K., Easa, A. M., Rosamah, E., ... \& Banerjee, A. (2017). Seaweed based sustainable films and composites for food and pharmaceutical applications: A review. Renewable and Sustainable Energy Reviews, 77, 353-362..

20. Kok, J. M. L., \& Wong, C. L. (2018). Physicochemical properties of edible alginate film from Malaysian Sargassum polycystum C. Agardh. Sustainable Chemistry and Pharmacy, 9, 87-94.

21. Lee, M. J., Seo, D. Y., Wang, I. C., Chun, N. H., Lee, H. E., Jeong, M. Y., .. \& Choi, G. J. (2012). Quantitative in-line monitoring of solvent-mediated polymorphic transformation of sulfamerazine by near-infrared spectroscopy. Journal of pharmaceutical sciences, 101(4), 1578-1586.

22. Mellinas, C., Valdés, A., Ramos, M., Burgos, N., Garrigos, M. D. C., \& Jiménez, A. (2016). Active edible films: Current state and future trends. Journal of Applied Polymer Science, 133(2).

23. Mellinas, C., Valdés, A., Ramos, M., Burgos, N., Garrigos, M. D. C., \& Jiménez, A. (2016). Active edible films: Current state and future trends. Journal of Applied Polymer Science, 133(2).

24. Olivas, G. I., \& Barbosa-Cánovas, G. V. (2008). Alginate-calcium films: water vapor permeability and mechanical properties as affected by plasticizer and relative humidity. LWT-Food science and technology, 41(2), 359-366.

25. Pereda, M., Ponce, A. G., Marcovich, N. E., Ruseckaite, R. A., \&Martucci, J. F. (2011). Chitosan-gelatin composites and bilayer films with potential antimicrobial activity. Food Hydrocolloids, 25(5), 1372-1381.

26. Ravi, S., Shanmugam, B., Subbaiah, G. V., Prasad, S. H., \& Reddy, K. S. (2017). Identification of food preservative, stress relief compounds by $G C-M S$ and $H R-L C / Q-T O F / M S$; evaluation of antioxidant activity of Acalypha indica leaves methanolic extract (in vitro) and polyphenolic fraction (in vivo). Journal of food science and technology, 54(6), 1585-1596.

27. Raybaudi-Massilia, R. M., Mosqueda-Melgar, J., \& Martín-Belloso, O. (2008). Edible alginate-based coating as carrier of antimicrobials to improve shelf-life and safety of fresh-cut melon. International journal of food microbiology, 121(3), 313-327.

28. Rezvanian, M., Amin, M. C. I. M., \& Ng, S. F. (2016). Development and physicochemical characterization of alginate composite film loaded with simvastatin as a potential wound dressing. Carbohydrate polymers, 137, 295-304.

29. Rhim, J. W. (2004). Physical and mechanical properties of water resistant sodium alginate films. LWT-Food science and technology, 37(3), 323-330.

30. Rhim, J. W. (2007). Potential use of biopolymer-based nanocomposite films in food packaging applications. Food Science and Biotechnology, 16(5), 691-709. 
31. Rhim, J. W., Kim, J. H., \& Kim, D. H. (2003). Modification of Na-alginate films by \$ CaCl_2 \$ treatment. Korean Journal of Food Science and Technology, 35(2), 217-221.

32. Rinaudo, M. (2008). Main properties and current applications of some polysaccharides as biomaterials. Polymer International, 57(3), 397-430.

33. Roger, S., Talbot, D., \& Bee, A. (2006). Preparation and effect of Ca2+ on water solubility, particle release and swelling properties of magnetic alginate films. Journal of Magnetism and Magnetic Materials, 305(1), 221-227.

34. Sellimi, S., Younes, I., Ayed, H. B., Maalej, H., Montero, V., Rinaudo, M., ... \& Nasri, M. (2015). Structural, physicochemical and antioxidant properties of sodium alginate isolated from a Tunisian brown seaweed. International journal of biological macromolecules, 72, 1358-1367.

35. Sköld, O. E., \&Swedberg, G. (2017). Sulfonamides and trimethoprim. In Antimicrobial Drug Resistance, Springer, Cham, pp.345-358.

36. Soazo, M., Báez, G., Barboza, A., Busti, P. A., Rubiolo, A., Verdini, R., \&Delorenzi, N. J. (2015). Heat treatment of calcium alginate films obtained by ultrasonic atomizing: Physicochemical characterization. Food Hydrocolloids, 51, 193-199.

37. Tačić, A., Nikolić, V., Nikolić, L., \& Savić, I. (2017). Antimicrobial sulfonamide drugs. Advanced technologies, 6(1), 58-71.

38. Van de Velde, K., \& Kiekens, P. (2002). Biopolymers: overview of several properties and consequences on their applications. Polymer testing, 21(4), 433-442.

39. Weber, C. J., Haugaard, V., Festersen, R., \& Bertelsen, G. (2002). Production and applications of biobased packaging materials for the food industry. Food Additives \& Contaminants, 19(S1), 172-177.

40. Wróblewska-Krepsztul, J., Rydzkowski, T., Borowski, G., Szczypiński, M., Klepka, T., \& Thakur, V. K. (2018). Recent progress in biodegradable polymers and nanocomposite-based packaging materials for sustainable environment. International Journal of Polymer Analysis and Characterization, 23(4), 383-395.

41. Yadav, P., Yadav, H., Shah, V. G., Shah, G., \& Dhaka, G. (2015). Biomedical biopolymers, their origin and evolution in biomedical sciences: A systematic review. Journal of clinical and diagnostic research: JCDR, 9(9), ZE21. 
